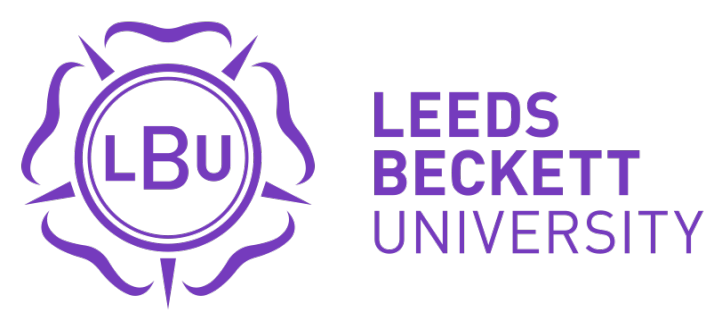

Citation:

Carless, D and Douglas, K (2008) Narrative, identity and mental health: How men with serious mental illness re-story their lives through sport and exercise. Psychology of Sport and Exercise, 9 (5). 576 - 594. ISSN 1469-0292 DOI: https://doi.org/10.1016/j.psychsport.2007.08.002

Link to Leeds Beckett Repository record:

https://eprints.leedsbeckett.ac.uk/id/eprint/364/

Document Version:

Article (Accepted Version)

The aim of the Leeds Beckett Repository is to provide open access to our research, as required by funder policies and permitted by publishers and copyright law.

The Leeds Beckett repository holds a wide range of publications, each of which has been checked for copyright and the relevant embargo period has been applied by the Research Services team.

We operate on a standard take-down policy. If you are the author or publisher of an output and you would like it removed from the repository, please contact us and we will investigate on a case-by-case basis.

Each thesis in the repository has been cleared where necessary by the author for third party copyright. If you would like a thesis to be removed from the repository or believe there is an issue with copyright, please contact us on openaccess@leedsbeckett.ac.uk and we will investigate on a case-by-case basis. 
Running head: NARRATIVE, IDENTITY AND MENTAL HEALTH

Narrative, Identity and Mental Health: How Men with Serious Mental Illness Re-story Their Lives Through Sport and Exercise

David Carless

Leeds Metropolitan University

Kitrina Douglas

University of Bristol

Published as: Carless, D. \& Douglas, K. (2008). Narrative, identity and mental health: How men with serious mental illness re-story their lives through sport and exercise. Psychology of Sport and Exercise, 9(5), 576-594.

Address for correspondence:

Dr David Carless

Leeds Metropolitan University

Carnegie Research Institute

Headingley Campus,

Beckett Park,

Leeds LS6 3QS, UK

Phone: 07879647227

Fax : 01132837575

Email: d.carless@leedsmet.ac.uk 


\begin{abstract}
Objectives: It has been suggested that mental illness threatens identity and sense of self when one's personal story is displaced by dominant illness narratives focussing on deficit and dysfunction. One role of therapy, therefore, is to allow individuals to re-story their life in a more positive way which facilitates the reconstruction of a meaningful identity and sense of self. This research explores the ways in which involvement in sport and exercise may play a part in this process.
\end{abstract}

Method: We used an interpretive approach which included semi-structured interviews and participant observation with 11 men with serious mental illness to gather stories of participants’ sport and exercise experiences. We conducted an analysis of narrative to explore the more general narrative types which were evident in participants' accounts.

Findings: We identified three narrative types underlying participants' talk about sport and exercise: (a) an action narrative about "going places and doing stuff”; (b) an achievement narrative about accomplishment through effort, skill or courage; (c) a relationship narrative of shared experiences to talk about combined with opportunities to talk about those experiences. We note that these narrative types differ significantly from - and may be considered alternatives to - dominant illness narratives.

Conclusion: This study provides an alternative perspective on how sport and exercise can help men with serious mental illness by providing the narrative resources which enabled participants to re-story aspects of their lives through creating and sharing personal stories through which they rebuilt or maintained a positive sense of self and identity.

Keywords: mental health, identity, physical activity, schizophrenia, narrative, therapy 
Narrative, Identity and Mental Health: How Men with Serious Mental Illness Re-story Their Lives Through Sport and Exercise

In this article we seek to contribute to dialogue regarding the psychological effects of sport and exercise participation for people with serious mental health difficulties (e.g., Beebe, Tian, Morris, Goodwin, Allen, \& Kuldau, 2005; Faulkner \& Sparkes, 1999; Fogarty \& Happell, 2005). As such, this work builds upon and develops existing studies (Carless, 2007, in press; Carless \& Douglas, 2004, in press; Carless \& Sparkes, 2007) which have explored the ways in which sport and exercise are experienced by men with serious mental illness such as schizophrenia. A central focus of our ongoing interpretive research is the ways in which involvement in sport and exercise can contribute to the process of recovery in the context of serious mental illness.

In doing this work we are sharply aware of Davidson and Roe’s (2007) observation that the "dynamic interactions between the complexities involved in serious mental illness with those complexities involved in the human beings who suffer from and recover from these illnesses result in an extremely complex terrain, about which we still know very little” (p. 460). In recognition of this uncertainty, we have chosen to utilise here a narrative psychological approach in an effort to shed new light on the ways sport and exercise are experienced by men with serious mental illness. Despite the increasingly widespread use of narrative approaches in mainstream psychology (see Crossley, 2000; Dimaggio, 2006), there are few examples of its use in physical activity and mental health research (see Carless \& Sparkes, 2007) and narrative approaches remain relatively rare in sport and exercise psychology in general (see Douglas \& Carless, 2006, in press; Smith, 1999; Smith \& Sparkes, 2002; Sparkes \& Partington, 2003; Sparkes \& Smith, 2003; Stelter, 2006). However, as Sparkes (2005) notes, this approach has the potential to enrich our understanding through developing "a more sophisticated appreciation of people as active social beings and focus 
attention on the way personal and cultural realities are constructed through narrative and storytelling” (p. 191). Before proceeding with this endeavour, it is first necessary to provide some background on the concept of recovery in the context of serious mental illness and the narrative theory which underlies our approach.

Recovery in the Context of Serious Mental Illness

According to several authors who have themselves experienced serious mental illness, there is more to recovery than the alleviation of symptoms, deficits, and dysfunctions (e.g., Baker-Brown, 2006; Chadwick, 1997; Deegan, 1996; Repper \& Perkins, 2003). When it comes to recovery, Repper and Perkins (2003) suggest

The challenge facing people with mental health problems is to retain, or rebuild, a meaningful and valued life, and, like everyone else, to grow and develop within and beyond the limits imposed by their cognitive and emotional difficulties. Recovery is not about 'getting rid' of problems. It is about seeing people beyond their problems their abilities, possibilities, interests and dreams - and recovering the social roles and relationships that give life value and meaning (p. ix).

A similar perspective has been more recently voiced by Davidson, O’Connell, Tondora, Lawless, and Evans (2005) who, in attempting to establish a conceptual framework for the concept of recovery, write

we have learned that recovery from serious mental illness does not require remission of symptoms or of other deficits. Rather, recovery involves incorporation of one's illness within the context of a sense of hopefulness about one’s future, particularly about one’s ability to rebuild a positive sense of self and social identity (p. 484-5). Rebuilding a sense of self and a social identity is an important aspect of Davidson and Roe's (2007) characterisation of recovery in serious mental illness which they suggest is needed to overcome the "loss of valued social roles and identity, isolation, loss of sense of self and purpose in life” (p. 462). A common theme in diverse conceptions of recovery, then, seems to 
us to revolve around the rebuilding or recreation of a sense of self, an identity, and a sense of purpose within meaningful social roles and relationships. In order to explore these complex issues, and begin to develop an understanding of how these kinds of changes might come about through involvement in sport and exercise, we now turn to consider the social constructionist conception of narrative theory which underpins this research.

\section{Narrative, Identity, and Mental Health}

Narrative theorists (e.g., Brooks, 1994; McLeod, 1997) have suggested that mental health is in some way related to one's ability to create a story of one's life. If this is the case, it seems likely that an important link between narrative and mental health concerns the way in which identity and sense of self may be developed and maintained through telling stories of our lives ${ }^{1}$. According to Crossley (2000), creating and telling stories of one’s life is a necessary part of developing and maintaining a coherent identity and sense of self because it is "through narrative [that] we define who we are, who we were and where we may be in the future” (p. 67). In this light, stories may be considered a way of linking one’s past, present, and future which allows the development of a coherent sense of self that 'makes sense' within the context of one’s life experiences. Spence (1982) suggests that “we are all the time constructing narratives about our past and future ... the core of our identity is really a narrative thread that gives meaning to life provided - and this is the big if - that it is never broken” (p. 458). The maintenance of a coherent narrative thread, according to McAdams (1993), provides a sense of meaning and purpose to one’s life which helps avoid malaise and stagnation. Indeed in Baldwin’s (2005) terms, “maintaining this sense of coherence is an overarching feature of a life-project and productive of well-being and (arguably) its loss is a feature of mental ill-health such as in schizophrenia or post-traumatic stress disorder” (p. 1023).

Importantly however, meaning and coherence are not inherent features of narratives, but instead are created in the act of telling stories. In their research with men who acquired 
spinal cord injury playing sport, Smith and Sparkes (2002) have shown how "coherence and the meaning of experience is artfully constructed, occasioned, circumstantially formed and influenced by the cultural conventions of telling” (p. 167). This finding is significant in that it begs the question of how a person might create meaning and coherence in the absence of storytelling opportunities. This is a real concern, we suggest, in mental health contexts as according to Baldwin (2005) the experience of serious mental illness can in itself deny individuals both the ability and the opportunity to author their own life story. As Baldwin (2005) puts it, as a result of “cognitive difficulties or loss of language, individuals may lose the ability to construct and articulate a coherent narrative” (p. 1023). Similarly, he suggests, an "individual's interactions with others may be restricted by a condition that results in decreased opportunities to launch and maintain narratives” (Baldwin, 2005, p. 1023). In this regard, problems with thought processes, communication, social withdrawal, and/or inactivity can together conspire to deny a person with serious mental illness the opportunity to both create and share stories of his or her life. A likely consequence of this denial, narrative theorists such as McLeod (1997) and Crossley (2000) suggest, is that individuals are thereby limited or restricted in terms of the avenues through which they may maintain or develop a coherent, meaningful life story by which to preserve or renew identity and sense of self. Narratives and Culture

It is significant that, while stories are personal, they are at the same time shaped by cultural factors. According to McLeod (1997), "Even when a teller is recounting a unique set of individual, personal events, he or she can only do so by drawing upon story structures and genres drawn from the narrative resources of a culture” (p. 94). Thus, a person’s own story is shaped and constrained by narratives that circulate within the culture in which he or she is immersed. Frank (1995) has described these as narrative types which he characterises as "the most general storyline that can be recognized underlying the plot and tensions of particular 
stories” (p. 75). In Frank’s terms, "People tell their own unique stories, but they compose these stories by adapting and combining narrative types that cultures make available” (p. 75).

In the context of serious illness, a powerful medical narrative acts to shape and constrain an individual's story about (and experience of) illness. Frank (1995) describes how, "The story of illness that trumps all others in the modern period is the medical narrative. The story told by the physician becomes the one against which all others are ultimately judged true or false, useful or not” (p. 5). In particular, Frank (1995) suggests, the restitution narrative, a storyline that is "filled out with talk of tests and their interpretation, treatments and their possible outcomes, the competence of physicians, and alternative treatments” (p. 77), influences many people’s experience of illness. The plot of this story, Frank suggests, follows the basic storyline of yesterday I was healthy, today I'm sick, but tomorrow I'll be healthy again.

While a restitution story may work for some illness experiences, it can be problematic in the context of serious or chronic illness for which a 'cure' (i.e., a return to previous health as it once was) may not be forthcoming. Restitution stories no longer work, Frank (1995) suggests, in the context of long-term impairment which equates to some people's experience of serious mental illness when restitution is not inevitable and a focus on the future can be problematic - or even hopeless - because a future free of illness cannot be envisaged. Frank (1995) and Smith and Sparkes (2005a) suggest that individuals experiencing chronic illness therefore need alternative narrative resources by which to story their lives in order to prevent narrative wreckage and thereby preserve or reinstate sense of self, identity, and mental health. At these times, as Baldwin (2005) puts it, "to challenge disabling master narratives, counterstories that are individual, enabling and meaningful need to be both constructed and realised” (p. 1027).

The Therapeutic Potential of Sport and Exercise 
According to McLeod (1997) and Baldwin (2005), an important component of therapeutic interventions for people with mental health problems is the opportunity to launch and maintain personal stories which reinstate a sense of meaning, identity and coherence in a person's life. In this regard, White and Epston (1990) suggest that therapy should “open space for persons to re-author or constitute themselves, each other and their relationships according to alternative stories or knowledges” (p. 75). In so doing, individuals are able to create and share a life story which 'makes sense' within the context of both their experience and the cultural narrative types available to them. According to McLeod (1997), this task is fundamental to psychological well-being and mental health in that "the task of being a person in a culture involves creating a satisfactory-enough alignment between individual experience and 'the story of which I find myself a part'” (p. 27).

How might involvement in sport and exercise contribute to this process? We suggest a key issue concerns the way that involvement in sport and exercise differs from mainstream pharmaceutical interventions in that it can go beyond removing problems by contributing something positive to a person's life. According to Anthony (1993), this distinction is important in recovery terms:

There is the possibility that efforts to positively affect the impact of severe mental illness can do more than leave the person less impaired, less dysfunctional, less disabled, and less disadvantaged. These interventions can leave a person with not only “less,” but “more” - more meaning, more purpose, more success and satisfaction with one's life (Anthony, 1993, p. 20).

Several positive benefits of this kind have been identified in existing literature. First, it appears that sport and exercise activities provide opportunities for social experiences and interaction which is valued by some users of mental health services (Carless \& Douglas, 2004; Carter-Morris \& Faulkner, 2003; Faulkner, 2005). Second, involvement in sport and exercise can bring a sense of meaning, purpose, optimism, and hope to the lives of some 
people with mental health problems (Carless \& Douglas, in press; Carless \& Sparkes, 2007; Raine, Truman, \& Southerst, 2002). Third, participation in sport or exercise can boost some people’s self-esteem (Faulkner, 2005; Faulkner \& Sparkes, 1999). Finally, sport and exercise helps some individuals rediscover a sense of identity (Carless, 2007, in press; Carless \& Douglas, in press).

While previous research suggests some important ways in which sport and exercise can help people with serious mental health difficulties, the question of how these changes come about is far from resolved. We suggest that the previously discussed social constructionist conception of narrative theory has the potential to provide fruitful insights into this question. Given that this project represents the first use of a social constructionist narrative approach to physical activity and mental health research, in keeping with the ethos of interpretive research we attempt to illuminate rather than pin down what Davidson and Roe (2007) recognise as “an extremely complex terrain, about which we still know very little” (p. 460). Our purpose therefore is to explore the ways in which narrative, identity and mental health relate to one another within the specific context of sport, exercise and serious mental illness. Specifically, we focus on developing understanding of how sport and exercise involvement can help some men with serious mental illness through providing opportunities for the creation and sharing of personal stories which facilitate the narrative (re)construction of identity and sense of self. We hope to achieve this by exploring the kinds of stories eleven men with serious mental illness told about their experiences of sport and exercise.

\section{Method}

\section{Participants and Procedures}

The interpretive approach used in this study was strongly influenced by our recognition of the potential challenges, difficulties, and risks of conducting research in the context of serious mental illness. In particular, given our desire to obtain first person narrative accounts of sport and exercise within the context of serious mental illness, it was necessary to 
conduct interviews which provided participants with opportunities to tell their own stories. According to Stone (2004), however, there is a risk in telling these kinds of personal stories in the context of mental illness:

to formulate a narrative will necessitate a willed passage into and through the same spaces of self - thought, memory and emotion - in which the illness has been, and possibly still is, manifest ... All of this, I want to suggest, means the narrative journey may be a perilous one. (p. 20)

In an effort to minimise the dangers which may arise from talking about and 'revisiting' potentially traumatic life phases, we employed two strategies of ethnographic research which we believed would reduce the risk of participants experiencing distress.

The first strategy involved striving to develop a high degree of trust, rapport, and familiarity with participants. Specifically, following ethical clearance from the NHS Trust Research Ethics Committee, I (David Carless) engaged in prolonged immersion in the field over an 18 month period where he participated in the daily life of a vocational rehabilitation centre for people with serious mental illness. During this time, I took part in sport and exercise groups as well as social and day-to-day activities which helped build trust and rapport with potential participants. For Kitrina Douglas, trusting relationships and familiarity with participants were established through Kitrina attending the centre on a weekly basis and coaching a golf activity group which was developed, organised, and run by both authors and offered alongside other physical activity sessions at the centre. Potential participants were identified on the basis of (i) their personal experience of both serious mental illness and sport/exercise participation; (ii) their willingness to take part in the research; and (iii) mental health professionals' assessment that the individual was sufficiently mentally well to participate. In total, 11 participants agreed to take part in the research and provided informed consent. At the time of the research participants were aged between 24 and 43 and all were considered to be experiencing severe and enduring mental illness. 
The second strategy involved utilising two distinct methods of data collection in an effort to gain a rich and broad understanding of the background and context of participant's experiences. These methods were: (a) Participant observation. During sport and exercise activities and day-to-day life at the rehabilitation centre field notes were compiled independently by both authors to document observations, interpersonal exchanges, and personal reflections; (b) Semi-structured interviews. A total of 16 interviews were conducted and each participant took part in between one and three interviews each lasting from 20 to 90 minutes in duration. Participants were invited to talk about: (i) their experiences in and through sport and exercise; (ii) particularly memorable sport or exercise-related moments; (iii) their previous sport and exercise involvement; (iv) any ways in which sport or exercise affected them. Prior to concluding the interview, participants were asked whether there was anything else they would like to share regarding their experience of sport, exercise, or mental health. Throughout the interviews, the researchers acted as 'active listeners' in an attempt to assist the participant to talk about his own experiences in his own words. The interviews were conducted within the familiar settings of the day centre or physical activity venue and were audio recorded and transcribed verbatim with the exception of an interview with one participant who did not want a tape recorder to be used.

\section{Analysis of Narrative}

The first stage of analysis involved both researchers engaging in several close readings of the interview transcripts and field notes to become immersed in the data. Next, we conducted a content analysis using quotations as the unit of analysis (Sparkes, 2005) and following the process described by Lieblich, Tuval-Mashiach, and Zilber (1998) as categorical-content analysis. The findings of these analyses have been presented elsewhere (Carless, 2007; Carless \& Douglas, 2004). However, as Lieblich et al. (1998) note, “while the content is often more obvious and immediate to grasp, researchers may prefer to explore the form of a life story because it seems to manifest deeper layers of the narrator's identity” (p. 
13). Thus we conducted a third stage of analysis which has been described by Smith and Sparkes (2006) as an analysis of narrative. These authors outline several alternative analytical approaches to narrative research and suggest that researchers should be clear in which approaches they employ in a particular study. For the purposes of this study, we adopted the standpoint of story analyst who thinks about stories. From this standpoint we treat stories as 'data' and use 'analysis' to arrive at, for instance, themes that hold across stories or delineate types of stories. That is, story analysts step outside or back from the story, employ analytical procedures, strategies, and techniques in order to explore certain features of the story (e.g., content or structure), and carefully engage in abstract theorization about the story from a sociological, psychological and/or other disciplinary perspective. (Smith \& Sparkes, 2006, p. 185)

This standpoint contrasts with that of a storyteller "who performs a narrative analysis and thinks with stories” (p. 185). In this class of inquiry, the product is a story which the researchers allow to stand alone without further analysis or interpretation (see Carless \& Sparkes, 2007 for an example of narrative analysis in action).

In this study, in Holstein and Gubrium's (2000) terms, our interest was primarily in the whats of storytelling (what happened to whom) as opposed to the hows (how the story is told). Thus, we conducted what Sparkes (2005) calls an analysis of structure and form of participants' stories in recognition that "the formal aspects of structure, as much as the content, express the identity, perceptions, and values of the storyteller” (Sparkes, 2005, p. 195). Specifically, this analysis adhered to the process described in detail by Lieblich et al. (1998) as a holistic analysis of form whereby we focused on "the formal plot and organisation of the narrative to tease out the distinct structures that hold it together with a view to identifying it as a particular narrative type” (Smith \& Sparkes, 2007, p. 27). Through identifying common narrative types underlying participants' stories of sport and exercise, we 
aimed to develop an understanding of the meaning of sport and exercise within participants' socio-cultural context.

Accordingly we now present our findings in the shape of three story types which were evident within participants' accounts of their sport and exercise experiences. We describe these as action, achievement, and relationship narratives and illustrate the ways in which these narrative types related to participants' experiences in the context of sport and exercise activities.

\section{Findings}

An Action Narrative: "Going places and doing stuff”

I like going out and about, like I said, people, you know, having a soft drink and stuff, playing with people, enjoy yourself ... keeping your mind busy, it’s going places and doing stuff.

A recurring motif around which participants' stories and talk about their sport and exercise involvement were structured was the concept of action. By 'action' we mean, in the words of one participant above, “going places and doing stuff.” In this regard, the action narrative incorporated an embodied experience of some kind, relating to some form of a physical process or bodily movement. For some, taking action - having something to do and somewhere to go - was expressed as being personally valued and meaningful even if only to the extent that it gave them a reason to get out of the house:

It's just that I've got an activity for the afternoon that I'm not sat watching TV something like that. I watch so much it just sort of draws me. I need to sort of break away from a day indoors and get out and do something ... Its something to get me out of bed, get out of bed that morning.

The action narrative is significant in that it differs markedly from the dominant narrative of serious mental illness which often revolves around inactivity, of not doing much and not having much to do, of withdrawing from life (see for example, Baker-Brown, 2006; Deegan, 
1996; Stone, 2006). For example, one participant described his experience of hospitalisation in a psychiatric ward: “I was just bored in there - nothing to do. I didn’t do much. I was so bored. I didn't hardly do nothing. I just stayed in the ward and just went to bed and that was it.” Similarly, stories of other phases of illness were commonly characterised by inactivity: “Over at my mother’s house I used to go to sleep a lot. I just switched off like ... I used to sleep for hours and hours.”

Participants told how taking action affected them in positive ways. One young man, for example, told how playing football (and being involved with football) provided a more positive focus for his thoughts because at these times, my mind's occupied. I think other things. I don’t really think about bad things that I might think about if I wasn’t doing something ... It can happen with other things but I think sport is such an active thing it tends to have that effect on me.

Other participants' action stories portray them as “keeping busy” through involvement in sport and exercise. The importance of this is illustrated in the following exchange:

Depression was my main problem. I suffered from depression and a bit of stress like. I think when I was young I overdone it like ... and what with our dad passing away as well like, that was another bout of depression I had as well like, went to the funeral and that sort of turned it on again like, you know ... but I feel good now. I feel OK now.

Interviewer: What do you thinks been able to change that?

Uh [pause]. Doing activities I think is the main thing - keeps me busy, you know. Another individual elaborated on how keeping busy through sport and exercise gave him the feeling that he was making good use of his time. Referring to his involvement with a five-aside football group, he said:

I enjoy it, have a sense of satisfaction that I actually played because I was doing something with my time. That's important I think - to actually be able to use your 
time properly ... I know I haven’t wasted my time, I’ve used my time constructively, doing something that'll do me good.

For him, "using time properly” related to his belief that, through participating in sport and exercise, he was engaging in an activity that would provide valued physical and psychological health benefits.

For those individuals who maintained their involvement, sport and exercise activities came to be a valued part of their weekly or daily routine or schedule. Referring to a community-based five-a-side league in which he had become involved, one participant remarked that,

It's a routine you get used to I think. Its like football, I get excited about football on a Monday. When you turn up there and watch other people play before you go on there, you get confident and you look forward to participating in the game like.

For some who voluntarily took part in sport and exercise groups, there was a sense that, in addition to being "used,” time passed quickly. In this sense there was a perception among some participants that through taking action and doing things, time sped up; that they no longer felt that they had endless time on their hands. A short exchange between two members of a nine-week golf programme, documented in our field notes, communicates a feel for this view: “Andrew went on to remark that 'These sessions seem to have gone ever so quickly.' Peter agreed, 'Yeah. I can’t believe it’s been two months since we started’” (16 July). In this regard, one individual described an afternoon playing golf at a local municipal course as "the best birthday I could have asked for.”

An Achievement Narrative: “That was way better than I ever thought I would have done”

A second type of narrative which was evident in participants' stories we characterise as an achievement narrative. Central to the achievement narrative are descriptions and accounts that focus on accomplishment, doing something well or of being successful, by virtue of 
effort, skill or courage. One individual, for example, told an achievement story in the context of long-distance running:

I went with a physio and done the Milwood 10k not last year the year before, [we] both ran round together ... That was good, gave me something to aim for. I stopped last time. I stopped in the Buxham as well. But this year I never stopped at all, I got all the way round on the Buxham and the Milwood. So that's an achievement isn't it? Importantly, achievement brought a range of positive feelings such as a sense of satisfaction from learning and performing skills:

Well, I get satisfaction from playing football. If I score a goal I'm pleased with myself and it gives satisfaction that way. Even if I didn't score a goal, some weeks when I haven’t scored, when I played well in defence or midfield ... football skills like trapping the ball, bringing it down and controlling the football and passing it using your alertness.

For others, a sense of achievement related to seeing their skills improve which subsequently increased their enjoyment of the activity as the following exchange illustrates:

Interviewer: How do you feel about your own play?

Well today it was brilliant because I got two threes and I can’t ever remember getting that! [laughs]

Interviewer: Do you feel you've changed over the two months at all in terms of golf? Hmmm [in a tone of agreement] [pause]

Interviewer: What's changed?

Um [pause]. I just think it’s got more enjoyable as it’s gone on.

Interviewer: What's that down to then?

Getting a couple of threes! [laughs]

Through participant observation we witnessed the way in which achievements resulted in displays of pleasure and satisfaction in individuals which were often shared with others in 
the activity group. A change in mood and demeanour, as a result of a good putting performance, is evident in the following description taken from our field notes:

In the second group, of Jerry, Peter and Harry it was Harry who particularly seemed pleased with his successes. Having been noticeably quiet in the café [beforehand], mostly looking down from under the peak of his cap towards the ground, he looked up, cheered and beamed a broad smile following his first 50 point score. (4 June)

Achievements, for some we suggest, related to positive feelings which were directly connected to an embodied sense of proficient movement, feel, and performance outcome. One participant, for example, described how making a good golf shot resulted in positive sensations of which he was clearly aware and which he found enjoyable:

Interviewer: How does it make you feel when you hit the good shots? Oh, lovely ... yeah, feels good. You know that you can do it, like. It gives you a bit of satisfaction ... when you connect with the ball, when you follow through with the ball, and the club, you make contact with the ball, it's that sort of swing like, and when you know you hit it - it’s that sound as well I think, you know, there's a good sound. Another individual linked his increasing competence at golf to a sense of optimism and hope concerning his ongoing improvement:

playing the round today I enjoyed it as far as I got. I started to get some slightly better scores, that didn't seem fluke-ish ... I feel that I'm making improvement and there's no reason why, if I carry on, I can’t improve my game.

Thus, achievements in the present often generalised to optimism and confidence regarding future activity. As one participant put it, "When you hit the ball, if you do something right, it gives you confidence, you feel as if you could do it again like. You get that feeling you could do it again.” 
Notwithstanding the challenges of learning new technical skills which any beginner will face, participants often came to perceive themselves as competent, skilled, and proficient at sport-related skills. This is illustrated by one participant's description of his own golf ability:

I know how to drive the ball, definitely, down a fairway. Cause I've done that quite a few times at the pitch and putt ... That's probably one thing I like about it - the driving shots I play. I get good distance on my driving shots ... When I'm driving, I think about distance and length - it's a good tip that for the serious golfer. In this remark, the individual identifies himself as a competent and 'serious' golfer. In so doing, he associates himself with both the culture of golf and with other golfers. This, we suggest, is potentially significant in that he is thereby able to tell a story about his life which revolves around achievement, success, and 'being good at' a specific activity which is culturally accepted and endorsed by others. In telling this story, he is able to incorporate 'being a golfer' within his identity and sense of self and, for this individual at least, this selfidentification is positive because he values golf and considers it to be a worthwhile activity. Thus, in creating and telling an achievement story in the context of a popular sport, he has a story which is shared by, and can potentially be shared with, many others in society.

A recurring motif within individual achievement stories was a sense of surprise at one’s own achievements. This was particularly evident among members of the golf group who either had never played golf before or who had not played since the onset of mental illness. As one individual put it, "I was surprised I could do it at all ... when I hit the ball I was amazed that it went anywhere.” In this regard, participants’ achievements frequently exceeded their own self-expectations as the following exchange illustrates:

Interviewer: Can you tell me about the most memorable shots that you've hit? Yes. One, was it a week or a couple of weeks ago, where I putted and unexpectedly got the ball into the hole! ... I couldn’t believe it, what I saw ... I felt chuffed - with disbelief! 
Likewise, another participant described being “amazed” by his most memorable golf shot: I hit a lovely one last week with the six-iron, you know, when we were out at [names pitch and putt course] ... on the first one - I couldn't believe it! I thought 'How the hell did I do that?' like. I thought, well I've got to try and remember what I'd actually done to hit that ball ... just sort of prepared for the shot, I just swung the club and it worked and I thought 'Oh, hurray!' like. Yeah, thought, you know, I've done it like ... It was amazing, I amazed myself really. I thought it wasn't going to work out that way.

These moments of surprise were not unusual. Frequently, as the following excerpt from our field notes illustrates, the pleasure and surprise at one's own successful performance prompted verbal interaction between the group members thus constituting a shared moment of celebration:

There was a great sense of excitement also among several individuals. Harry regularly called out excitedly, “Whoa! It’s on the green!” while Andrew several times gasped “Ooooh!” in response to his better shots. On the first hole, following a fairway shot, Andrew exclaimed, "Hey! That was way better than I ever thought I would have done!” (9 July)

\section{A Relationship Narrative: "Sharing a common thing”}

Well you're meeting other people that are sharing a common thing aren't you really? Common exercises, sharing that experience. That's what I reckon anyway. So it’s good on that side of it ... all doing the same thing, got the same experience and got something to talk about.

The third type of narrative evident in participants' talk about sport and exercise we characterise as a relationship narrative. As the excerpt above suggests, shared experience and interaction with others were hallmarks of these stories. For several participants, it was the opportunity of a social time with others, of being with and sharing time and/or an activity 
with others, that served as their primary motive for sport and exercise. This is illustrated in the following exchange:

Interviewer: So, have you played any golf before?

No. I have never played golf in my life. This is the first time.

Interviewer: Do you watch it on TV?

No I'd get bored.

Interviewer: So no interest in golf?

Not interested in golf, not really.

Interviewer: So why did you decide to join this group?

'Cause there's a lot of people - the social - you can enjoy. Otherwise, I'm bored, do you understand me? There's people there, that's what I like to enjoy ... I like being with people you see, I like being social, I like having a laugh and stuff like that. I don’t like sitting on my own with my thoughts, d'you understand me? ... I like being with people. That's it.

For this individual, it is quite clear that the activity was of little interest in itself. However, he joined and regularly attended a golf programme on the basis of the social opportunities it provided. Within his description is a sense that this form of social involvement provided a focus for his thoughts that was preferable to spending time on his own.

A social orientation was very common among many participants who valued the opportunity to meet and make new friends through sport and exercise. When asked about his experience of being a member of a sport group, one participant replied:

It's a good social activity to be with them. It's a good time, to be with them. And you can learn by other people, what they've done as well I think, you can talk about it, you know. They'll probably ask, the other person, how you felt, and I think that's how you learn ... it's a good atmosphere ... It's different when you're not with a group as well 
isn't it like? You get cut off a little bit don't you? I mean the atmosphere's not there so much, know what I mean?

This sense of social "atmosphere” or occasion was something that we observed during groupbased sports activities as the following excerpt from our field notes illustrates:

There seemed to be no inter-personal problems whatsoever. In fact, the group members were hugely generous and supportive of each other. One example was when William hit the ball off the tee ninety degrees into the rough. Immediately, Harry shouted out "You can have that again.” Ronnie agreed, "Yeah, he can have it again!” Similarly, on Harry holing out, Ronnie walked over and offered a 'fist handshake' and verbal congratulations. (9 July)

A sense of support and consideration towards each other was also characteristic of these relationship stories and evident in many of the group activity sessions. One participant explicitly described the support he felt he gained through the various sport and exercise groups he attended:

Well I'm sort of supported. I feel supported with other people there, yeah. It's people that I know mainly, especially like with the football team, its people that I never knew before but I got friendly with - made good friends - and we all just participated in sport.

Often mutual support and consideration was unexpressed in verbal form during interviews being, instead, something that we observed enacted or unfolding within the dynamics of a group. As such, 'miniature stories’ of consideration and generosity were not uncommon within day-to-day exchanges between group members. One example of this kind of relational orientation is demonstrated in the following excerpts from our field notes which, while referring to the same event, were recorded by both researchers independently:

Prior to the round, Richard had offered Chris a roll-up cigarette. Chris had replied “Are you sure? Thanks very much” with an air of pleasant surprise that suggested 
perhaps it was not common for cigarettes to actually be offered round. On the $6^{\text {th }}$ tee, Chris returned the generosity by asking whether Richard or I would like a cigarette. (16 July)

There is a gentleness and mutual respect between the group members. Typical of this are simple things like offering someone a cigarette ... Richard offered Chris a cigarette and Chris humbly looked and asked if Richard was sure. He asked in such a way that he gave away from his question that he took nothing for granted, that Richard didn’t have to offer, it wasn't expected. (16 July)

\section{Discussion}

Clearly, any research approach has inherent strengths and limitations. There are three limitations which we feel are particularly relevant to this research. First, we have focussed exclusively on men's experience of sport and exercise. Further research is needed to explore the ways in which women with serious mental health problems experience sport and exercise. In light of generally lower participation rates among women, and the different socio-cultural significance of sport and exercise for women, we suspect that women's stories will differ markedly from men’s. Second, as Smith and Sparkes (2005b) observe, one potential weakness of this type of analysis by itself is that it often fails, if one is not careful, to acknowledge or illuminate the manner in which narrative structures may be dynamic and fluid, composed in the spaces between performer and audience, and thus situated in accomplished social action. (p. 234)

One way of guarding against this weakness is to engage in repeated interviews in order to explore how an individual's stories might change over time and in different social contexts. Given the challenges facing researchers in serious mental illness contexts (see Carless \& Douglas, in press; Carless \& Faulkner, 2003; Faulkner \& Carless, 2006; Faulkner \& Sparkes, 1999 for discussion), and in particular the risks of the narrative enterprise in this context (see Stone, 2004), ethical issues prevented repeated interviews with most participants. In addition, 
ethical considerations prohibited conducting interviews during the acute psychotic stage of illness. Among the 11 participants, several did not wish or were not able to engage in an extended series of interviews. To guard against this potential weakness, our solution was to include observational data of a more naturalistic kind in order to explore participants’ interactions, talk and social exchanges outside interview contexts. We suggest, however, that further exploration of the dynamic and fluid nature of narratives over time and in alternative social contexts is likely to be a fruitful topic for future research.

A third potential limitation concerns our identification of specific narrative types which risk “creating yet another general unifying view that subsumes the particularity of individual experience” (Smith \& Sparkes, 2005b, p. 234). To counter this risk we emphasise that action, achievement, and relationship narratives are not the only kinds of stories men might tell about sport and exercise and share Frank’s (1995) view that other types of narratives can and should be proposed. Following Frank (1995), we emphasise that our suggestion of three underlying narrative types “does not deprecate the originality of the story any individual ill person tells, because no actual telling conforms exclusively to any of the three narratives” (p. 76). In this regard, participants’ stories are unique and, as Frank notes, different narrative types are told alternately and repeatedly. Although participants often exhibited a preference for a particular narrative type, all participants told different types of story at different moments in time. Thus we hope these narratives types raise awareness of possible alternatives to the dominant medical narrative and that they may be used as listening devices (Frank, 1995) to allow these stories to be heard.

In terms of strengths, the three narrative types provide valuable insights into the ways sport and exercise is experienced by men with serious mental illness. Of particular relevance, we suggest, is that our analysis of participants’ stories shows how sport and exercise involvement can contribute to at least four of the nine common elements of recovery (redefining self, being involved in meaningful activities, being supported by others, and 
renewing hope and commitment) identified in the consumer/survivor and psychiatric rehabilitation literature by Davidson and colleagues (2005). A further strength of this narrative approach is that it allows psychologists to understand how sport and exercise came to be construed as meaningful activities by these men who are living with mental illness. As Smith and Sparkes (2005b) note, a narrative analysis of structure and form sheds light on the ways in which participants both create meaning and develop self and identity through sharing stories of their experiences. Because, as Dimaggio (2006) notes, "individuals use storytelling to give meaning to their experience, negotiate the meaning of events, make choices in the social sphere, and build up an identity” (p. 103), analysis of their stories provides insights into the constitutive process of meaning making and identity development in action. Finally, we suggest that the narrative types are also potentially significant in the more general context of enduring mental illness. We would like to explore this significance now by considering the three narrative types in relation to existing literature and theory concerning the experience of psychosis (Stone, 2006), illness narratives (Charmaz, 1991; Smith \& Sparkes, 2005a; Sparkes \& Smith, 2003), and the ways in which these narratives may be viewed from the perspective of social constructionist conceptions of narrative therapy (McLeod, 1997).

\section{The Experience of Psychosis}

In terms of the relationship between narrative and mental illness, Stone (2006, p. 44) identifies three (interrelated) themes in published stories of psychotic illness. First, "psychosis effects a suspension from the social realm.” Second, this suspension is experienced as "a muting agent: it involves the loss of speech ... and this in turn absents [a person] from the consensual world of discourse and action.” Third, many narrative accounts of psychotic illness communicate a "radical disruption to a settled sense of identity, a felt impression that selfhood and being are under imminent threat of complete disaggregation.” Narrative processes, Stone (2006) suggests, have the potential to help tackle these challenges. By storying one's experiences in the first person 'I', “a self, or a sense of selfhood, is established 
which enables the speaker to look outside herself from that position” (p. 47). Thus, an individual is able to reduce his or her self-focus and become more aware of others. According to Stone (2006) this focussing outside the self, through attending to the external, interpersonal realm, can act "as a counterweight to the internalizing energies of psychosis” (p. 47).

The points Stone (2006) identifies are demonstrated within participants’ stories of sport and exercise. First, the participants' stories are invariably told in the first person 'I'. In itself this simple act may be important in establishing a sense of selfhood based upon one's own lived experience. Second, group-based sport and exercise activities provided a way in which participants were able to reconnect with the social realm. This connection is underscored by the relational focus inherent in participants' stories of sport and exercise. Lieblich and colleagues (1998) define the term relational as "an emphasis on interpersonal dimensions rather than the separate self” (p. 87). The presence of relationship stories within men's accounts of sport and exercise suggest a high degree of external focus on interpersonal dimensions which contrast with those narratives of serious mental illness which may be characterised by a strong self-focus. Finally, as the preceding stories evidence, sport and exercise provided concrete opportunities for speech and interaction which all participants made use of.

\section{Chronic Illness Narratives}

Charmaz (1991) describes a change in a woman who became chronically ill in the following terms: "Before she became ill, she had worked towards future goals. Afterwards, she sought valued moments and good days in the present” (p. 3). In many ways, participants' stories of sport and exercise have much in common with this description as, when they talked about activity, their stories were almost exclusively focussed on the present - the here and now - and on valued moments and good experiences within this present. Notably, this present focus was not only inherent in participants' talk during interviews (which might have arisen through the tense of our questions) but was also documented through participant observation 
of informal interaction. A focus on the present, as opposed to the past or the future, is significant in that it signifies a departure from the dominant restitution story of illness. Restitution stories, Sparkes and Smith (2003) suggest, with their focus on 'cure' and returning a person to 'health', are necessarily oriented towards reinstating the past in the future - a future in which wellness is expected to return. Implicit therefore within the restitution narrative is a sense that the 'sick' present is undesirable, painful, and best avoided, to be replaced by a focus on a 'healthy' future.

The temporal focus of participants' stories is significant in relation to Sparkes and Smith's (2003) discussion of the narrative construction of self in the context of chronic illness. In these authors' terms,

The restitution narrative frames biographical time within a philosophy of the future that interweaves the three time tenses of Past in the future, the Present in the past, and the Future in the past. Time experienced in such ways connects the individual to notions of a restored and entrenched self that has its reference point firmly in the past, all of which makes it difficult to develop different senses of self and explore alternative identities in the present. (p. 315)

By telling action, achievement, and relationship stories focussed on a present in which they kept busy and used time effectively, the participants in this research distanced themselves from telling potentially problematic future or past-oriented restitution stories. In so doing, we suggest each participant was able, as Charmaz (1991) describes, to locate his sense of self, to a greater or lesser extent, in a real and authentic present (rather than some previous remembered past or some hoped for but distant future). Significantly, this real and authentic present became available for narration through embodied involvement in sport and exercise.

We suggest that telling action, achievement, and relationship stories focussed on the present enabled participants to re-story their lives in ways that allowed the exploration of alternative identities and selves. In this way, as Smith and Sparkes (2005a) suggest in relation 
to their narrative research with men who experienced spinal cord injury through sport, these three narrative types may be considered as potential counterstories (Baldwin, 2005) or counter-narratives (Nelson, 2001) to the illness-focussed restitution story which dominates many people’s experience of chronic illness. According to Nelson (2001), counter-narratives are "tools designed to repair the damage inflicted on identities by abusive power systems" which aim to "re-identify such people as competent members of the moral community and in doing so enable their moral agency" (p. xiii). Smith and Sparkes (2005a) suggest that "the potential for reconstructing self stories is enhanced when access is gained to counternarratives that provide alternative maps and different emplotments regarding disability and impairment” (p. 1100). Given that mainstream culture provides few (if any) alternatives to restitution-focussed illness stories (Smith \& Sparkes, 2007), we suggest that awareness of the three narrative types identified here may help some men with serious mental illness develop alternative identities and notions of self.

\section{Narrative Resources and Adventure}

In terms of the narrative reconstruction of lives and identities, it is generally recognised that people require resources, of some kind or another, in order to be able to re-story their lives (McLeod, 1997). Of particular interest in the context of this study is Scheibe’s (1986) suggestion that people require adventures in order to construct and maintain satisfactory life stories. The Concise Oxford Dictionary defines adventure as “an unusual, exciting, or daring experience” and we think this definition captures the place of sport and exercise held in some participants’ lives. According to McLeod (1997):

Different people may draw upon different sources of adventure. However, each type of adventure gives the person a ready supply of stories through which to create an identity both in the form of an on-going self-narrative but also a narrative that is shared with, and co-constructed with, other people. Adventurous activities also furnish 
a reference group of others willing to listen to these stories, as in groups of anglers

'swapping' tales of fish caught and fish that got away. (p. 43)

As McLeod (1997) suggests, 'adventure’ means different things to different people - football, for example, may constitute an adventure for one but not for another. However, among the men in this research, most were able to find a form of group-based sport or exercise which they experienced as adventure and which provided concrete, embodied experiences to talk about (in the form of action and achievement stories), alongside day-to-day opportunities to share these stories with others (in the form of relationship stories). As such, sport and exercise activities were simultaneously a shared experience to talk about and an opportunity to talk. In other words, involvement in sport and exercise provided an arena in which personal stories, in the form of action, achievement, and relationship narratives, were both created and told. For some, we suggest, the opportunity to launch and maintain these self stories facilitated a new sense of meaning and purpose through a reconstruction of identity and sense of self.

\section{Conclusion}

In summary, this article represents a modest attempt to bring the insights of social constructionist narrative theory to the under-researched topic of sport and exercise among people with serious mental health problems. Our findings highlight an alternative way in which involvement in sport and exercise can enhance the lives of men with serious mental illness, namely through providing the narrative resources which enables them to create and share positive personal stories which differ markedly from dominant and more negative narratives of mental illness. Through telling present-focused stories of their sport and exercise experiences, built around the notions of action, achievement, and relationships, it seems to us that participants were able, to a greater or lesser extent, to re-story their lives through reconstructing or sustaining a more positive, hopeful, and meaningful identity and sense of self independent of mental health culture. 


\section{Acknowledgements}

Thanks to the mental health professionals who facilitated this research, Brett Smith for his insightful comments on an earlier draft of the article, and the two anonymous reviewers for their comments. In particular, thanks to the participants for generously sharing with us stories of their sport and exercise experiences. 


\section{References}

Anthony, W. (1993). Recovery from mental illness. Innovations and Research, 2(3), 17-25.

Baker-Brown, S. (2006). A patient’s journey: living with paranoid schizophrenia. British Medical Journal, 333, 636-638.

Baldwin, C. (2005). Narrative, ethics and people with severe mental illness. Australian and New Zealand Journal of Psychiatry, 39, 1022-1029.

Beebe, L., Tian, L., Morris, N., Goodwin, N., Allen, S. and Kuldau, J. (2005). Effects of exercise on mental and physical health parameters of persons with schizophrenia. Issues in Mental Health Nursing, 26, 661-676.

Brooks, P. (1994). Psychoanalysis and Storytelling. Oxford, Blackwell.

Carless, D. (2007). Phases in physical activity initiation and maintenance among men with serious mental illness. International Journal of Mental Health Promotion, 9(2), 17-27.

Carless, D. (in press) Narrative, identity, and recovery from serious mental illness: A life history of a runner. Qualitative Research in Psychology.

Carless, D., \& Douglas, K. (2004). A golf programme for people with severe and enduring mental health problems. Journal of Mental Health Promotion, 3(4), 26-39.

Carless, D., \& Douglas, K. (in press). The role of sport and exercise in recovery from mental illness: Two case studies. International Journal of Men's Health.

Carless, D., \& Faulkner, G. (2003). Physical activity and mental health. In J. McKenna, \& C. Riddoch, Perspectives on Health and Exercise (pp. 61-82). Houndsmills: Palgrave MacMillan.

Carless, D., \& Sparkes, A. (2007). The physical activity experiences of men with serious mental illness: Three short stories. Psychology of Sport and Exercise, doi:10.1016/j.psychsport.2007.03.008 
Carter-Morris, P., \& Faulkner, G. (2003). A football project for service users: the role of football in reducing social exclusion. Journal of Mental Health Promotion, 2, 24-30.

Chadwick, P. (1997). Schizophrenia: The Positive Perspective. London, Routledge.

Charmaz, K. (1991). Good Days, Bad Days: The Self in Chronic Illness and Time. New Brunswick, NJ: Rutgers University Press.

Crossley, M. (2000). Introducing Narrative Psychology: Self, Trauma and the Construction of Meaning. Open University Press.

Davidson, L., O’Connell, M., Tondora, J., Lawless, M., \& Evans, A. (2005). Recovery in serious mental illness: a new wine or just a new bottle? Professional Psychology: Research and Practice, 36(5), 480-487.

Davidson, L., \& Roe, D. (2007). Recovery from versus recovery in serious mental illness: One strategy for lessening confusion plaguing recovery. Journal of Mental Health, 16 (4), 459-470.

Deegan, P. (1996). Recovery as a journey of the heart. Psychiatric Rehabilitation Journal, (19)3, 91-97.

Dimaggio, G. (2006). Disorganized narratives in clinical practice. Journal of Constructivist Psychology, 19, 103-108.

Douglas, K., \& Carless, D. (2006). Performance, discovery, and relational narratives among women professional tournament golfers. Women in Sport and Physical Activity Journal, 15(2), 14-27.

Douglas, K., \& Carless, D. (in press). The team are off: Getting inside women’s experiences in professional sport. Aethlon.

Faulkner, G. (2005). Exercise as an adjunct treatment for schizophrenia. In: G. Faulkner, \& A. Taylor, (Eds.), Exercise, health and mental health: emerging relationships (pp. 27-45). London: Routledge. 
Faulkner, G., \& Carless, D. (2006). Physical activity in the process of psychiatric rehabilitation: Theoretical and methodological issues. Psychiatric Rehabilitation Journal, 29(4), 258-266.

Faulkner, G., \& Sparkes, A. (1999). Exercise as therapy for schizophrenia: An ethnographic study. Journal of Sport \& Exercise Psychology, 21(1), 52-69.

Fogarty, M., \& Happell, B. (2005). Exploring the benefits of an exercise program for people with schizophrenia: A qualitative study. Issues in Mental Health Nursing, 26, 341-351.

Frank, A. (1995). The Wounded Storyteller. Chicago: University of Chicago Press.

Frank, A. (2000). The standpoint of storyteller. Qualitative Health Research, 10(3), 354-365.

Holstein, J., \& Gubrium, J. (2000). The Self We Live By. New York: Oxford University Press.

Lieblich, A., Tuval-Mashiach, R., \& Zilber, T. (1998). Narrative Research: Reading, Analysis and Interpretation. London: Sage.

McAdams, D. (1993). The Stories We Live By. New York, NY: The Guildford Press. McLeod, J. (1997). Narrative and Psychotherapy. London: Sage.

Nelson, H. (2001). Damaged Identities, Narrative Repair. Ithaca: Cornell University Press.

Raine, P., Truman, C., \& Southerst, A. (2002). The development of a community gym for people with mental health problems: Influences on psychological accessibility. Journal of Mental Health 11(1), 43-53.

Repper, J., \& Perkins, R. (2003). Social Inclusion and Recovery. Edinburgh, Balliere Tindall.

Scheibe, K. (1986). Self-narratives and adventure. In T. Sarbin (Ed.), Narrative Psychology: the Storied Nature of Human Conduct, (pp. 129-151). New York: Prager. 
Smith, B. (1999). The Abyss: Exploring depression through a narrative of the self. Qualitative Inquiry, 5(2), 264-279.

Smith, B., \& Sparkes, A. (2002). Men, sport, spinal cord injury, and the construction of coherence: Narrative practice in action. Qualitative Research, 2 (2), 143-171

Smith, B., \& Sparkes, A. (2005a). Men, sport, spinal cord injury, and narratives of hope. Social Science and Medicine, 61, 1095-1105.

Smith, B., \& Sparkes, A. (2005b). Analyzing talk in qualitative inquiry: exploring possibilities, problems, and tensions. Quest, 57, 213-242.

Smith, B., \& Sparkes, A. (2006). Narrative inquiry in psychology: exploring the tensions within. Qualitative Research in Psychology, 3, 169-192.

Smith, B., \& Sparkes, A. (2007). Sport, spinal cord injury, and body narratives: A qualitative project. Health Psychology Update, 16(3), 26-33.

Sparkes, A. (2005). Narrative analysis: exploring the whats and the hows of personal stories. In: I. Holloway, (Ed.), Qualitative Research in Health Care (pp. 191-209). Milton Keynes: Open University Press.

Sparkes, A., \& Partington, S. (2003). Narrative practice and its potential contribution to sport psychology: the example of flow. The Sport Psychologist, 17, 292-317.

Sparkes, A., \& Smith, B. (2003). Men, sport, spinal cord injury and narrative time. Qualitative Research, 3(3), 295-320.

Spence, D. (1982). Narrative persuasion. Psychoanalysis and Contemporary Thought, 6, 457-481.

Stelter, R. (2006). Team development in a relational perspective. In F. Boen, B. De Cuyper \& J. Opdenacker (Eds.), European Developments in Exercise and Sport Psychology (pp. 47-58). Leuven: Lannoo.

Stone, B. (2004). Towards a writing without power: notes on the narration of madness. Auto/Biography, 12, 16-33. 
Stone, B. (2006). Diaries, self-talk, and psychosis: writing as a place to live.

Auto/Biography, 14, 41-58.

White, M., \& Epston, D. (1990). Narrative Means to Therapeutic Ends. New York: Norton.

\footnotetext{
${ }^{1}$ The terms narrative and story are used interchangeably by some authors. We follow Frank (2000) in using the term story to refer to a personal experiential account as told by a specific individual and the term narrative to refer to the more general structure underlying a particular story.
} 